\title{
Resenha
}

\section{Dos românticos a Nietzsche. Oito estudos sobre a Filosofia do século XIX.}

\author{
ARALDI; Clademir Luís. Do \\ Romantismo a Nietzsche: Rupturas \\ e Transformações na Filosofia do \\ século XIX. Pelotas: Dissertatio \\ Filosofia, 2017.
}

Tulipa Martins Meireles*

Compreendemos que o período moderno e contemporâneo da história da filosofia ocidental é permeado pelo sentimento de crise e crítica vivenciado pelo ser humano europeu no final do século XVIII e ao longo do século XIX. Nesse contexto, o indivíduo passa a perceber a si mesmo a partir do estabelecimento das novas estruturas do mundo moderno que afetam sua maneira de viver. Após o triunfo científico e a derrocada dos ideais religiosos e humanistas próprios de uma sociedade dominada pela secularização e industrialização das massas, a constituição do sentido da vida e das formas de existir encontram na criação artística, na concepção de Subjetividade, própria do Gênio, e na noção de Natureza criadora uma forma de

* Doutoranda da Universidade Federal de Pelotas, UFPEL, Pelotas, RS, Brasil.

Correio eletrônico: tulipameireles@hotmail.com 
Meireles, T. M.

unir o Espírito com a Natureza, a Ciência com a Arte. Essa atitude, como manifestação do sentimento e do conflito entre a interioridade inquieta e a realidade racionalizada, tanto quanto os esforços por preencher o "vazio moderno" a partir de ideais laicizados como os de progresso, razão e ciência, parece ter ocupado grande parte do pensamento dos artistas e filósofos da época, assumindo sua forma mais acabada e radical no pensamento tardio de Nietzsche ${ }^{1}$.

Em Do Romantismo a Nietzsche: Rupturas e Transformações na Filosofia do Século XIX encontramos uma seleção de estudos que oferecem um desenvolvimento para essa temática. A obra foi publicada em 2017 e constitui-se do material produzido em 2015 para a disciplina História da Filosofia Moderna e Contemporânea do curso de Licenciatura em Filosofia a Distância da Universidade Federal de Pelotas (CAPES - UAB). Ao selecionar os oito estudos que compõem essa obra e ao discutir com pensadores como Karl Löwith e Eric Hobsbawn, o autor propõe uma investigação sobre as "rupturas e transformações que se deram no âmbito da Filosofia Moderna e Contemporânea". Essas transformações são tentativas de responder a questão: "Como a Filosofia reage ao triunfo das ciências naturais e da industrialização no século XIX?" (p. 2). Conforme expõe, o século XIX sentiu o impacto de dois importantes acontecimentos: a dupla revolução, francesa e industrial e o progresso tecnocientífico do mundo. Sua hipótese é que a dupla revolução no mundo ocidental e a consequente transformação no modo de viver das pessoas, gerou um desconforto por parte do indivíduo que sentiu o vazio deixado pela crise dos antigos valores que resultou em certo sentimento de perda do sentido da própria existência. A essa crise, a Filosofia encontrou nas noções de arte, natureza e subjetividade uma forma

1 Assim, percebemos que se a ideia que dominou o século XX deixou de lado a compreensão das raízes românticas do século XIX, o historiador Eric Hobsbawm em A Era das Revoluções: Europa 1789-1848 (1998) apreendeu diferentemente esse significado, atribuindo grande valor a Filosofia da Natureza Romântica para o século XIX, contribuindo inestimavelmente para o pensamento filosófico contemporâneo, na mesma esteira seguida por Araldi.

280 | Cad. Nietzsche, Guarulhos/Porto Seguro, v.39, n.3, p. 279-292, setembro/dezembro, 2018. 
Dos românticos a Nietzsche. Oito estudos sobre a Filosofia do século XIX

de conceber, pela via da arte, um caminho fecundo na direção de uma nova concepção de vida.

Nesse contexto, o Romantismo apresenta-se como uma das primeiras reações à secularização e à racionalização, propondo a criação artística e a Filosofia da arte como crítica às estruturas modernas, a partir da qual era possível ressignificar o mundo. $\mathrm{O}$ ímpeto revolucionário da arte e da criação artística perpassa os oito estudos propostos pelo autor, que encontra traços da atitude romântica de Schelling a Hegel, passando pelo Idealismo de Fichte e de Marx a Nietzsche, passando por Schopenhauer, Kierkegaard e o materialismo de Feuerbach. Nietzsche é apresentado como o filósofo que sustenta a crítica mais radical da modernidade. Ao anunciar a morte do Deus cristão como advento fundamental e a radicalização do niilismo moral consequente, o filósofo sustentaria a necessidade de instaurar um projeto de "transvaloração dos valores", a partir do qual a criação de valores afirmativos da vida seriam possíveis.

O livro integra oito Capítulos e é precedido por uma Apresentação, na qual o autor expõe o tema geral, as principais problemáticas que serão tratadas e o desenvolvimento dessas questões por parte dos filósofos. A proposta dos românticos a Nietzsche torna visível tanto a crise da filosofia metafísica e moral como os novos caminhos que se abrem para a filosofia nessa época de crise e crítica da modernidade. Nelas são valorizadas as especulações românticas, assim como o reino da arte, no seio de uma época secularizada e dominada pela ciência natural. Araldi apresenta a riqueza do pensamento filosófico do século XIX, quando a modernidade passa a pensar a autossuperação de si mesma.

O capítulo 1, intitulado Os românticos e o idealismo alemão, é dividido em dois tópicos: Gênio, natureza e sentimento e Schelling e a filosofia da arte romântica. $\mathrm{O}$ autor apresenta o Romantismo como um movimento cultural, artístico e filosófico que pretendia através arte, do gênio artístico e criador, revolucionar todas as estruturas 
Meireles, T. M.

do mundo moderno. O Romantismo é caracterizado pelas noções de Subjetividade, próprias do gênio criador, de arte e de Natureza que se apresentavam como atitude, maneira de viver e movimento cultural e filosófico que tinham como objetivo preencher o "vazio da modernidade" a partir da união entre Espírito e Natureza. Pela arte e pela obra de arte os românticos manifestavam o caos e o desconforto que traziam dentro de si. Mesmo não sendo um movimento homogêneo, os românticos tinham em comum a busca pela "fuga da modernidade" que se dava no âmbito do refúgio em um passado remoto ou na projeção de um futuro utópico.

No contexto da "dupla revolução", românticos como Hölderlin, Schlegel, Schelling e Schopenhauer consideravam que a Filosofia e a vida filosófica encontravam-se ameaçadas tanto pela política, como pela economia e pela ciência. Conforme Araldi, "A modernidade é marcada por abalos das estruturas religiosas, políticas e culturais tradicionais, assim como pelo pressentimento de novas formas de vida" (p. 9). Segundo ele, os românticos tinham consciência de que estavam vivendo em um período de transição para uma "nova era".

Schelling é o considerado o principal filósofo do Romantismo, por ter construído uma Filosofia da Natureza que é também uma Filosofia da arte. Seu pensamento foi uma tentativa de unir a filosofia de dois pensadores importantes para o Romantismo: Fichte, filósofo da Subjetividade, que influenciou diretamente os românticos por ter valorizado o Espírito (Eu Absoluto) em sua Filosofia Idealista, e Goethe, através de sua concepção de Natureza criadora. Para Schelling, a Natureza possui um valor tão elevado quanto o Espírito, sendo também ela incondicionada, dinâmica e viva. O princípio originário em Schelling, como união entre Natureza e Espírito, não é, contudo, inteiramente racional e consciente, pois o Espírito não é somente razão, mas sobretudo vontade originária. Ainda que diferente de Schopenhauer, para quem a vontade é a própria origem consciente do mundo, a vontade para Schelling anseia pela consciência. A

282 | Cad. Nietzsche, Guarulhos/Porto Seguro, v.39, n.3, p. 279-292, setembro/dezembro, 2018. 
Dos românticos a Nietzsche. Oito estudos sobre a Filosofia do século XIX intuição estética, própria do gênio artístico, é considerada a via privilegiada para alcançar o princípio originário, pois a criação artística é o meio de tornar concreta a manifestação do Espírito. Schelling é nesse sentido considerado o pensador que traz os traços mais marcantes do Romantismo em sua Filosofia da arte, que é desenvolvida principalmente na obra Ideias para uma filosofia da natureza (1797).

O capítulo 2, intitulado De Fichte a Hegel: idealismo subjetivo e dialética especulativa, é composto por dois tópicos: Fichte e o idealismo da subjetividade e Dialética especulativa de Hegel. Segundo o autor, Fichte foi o filósofo que pretendeu unificar os antagonismos herdados da filosofia kantiana, tentando superar o dualismo entre o mundo da necessidade natural e o mundo do Espírito, da liberdade. Fichte fez a opção pela supressão de um dos termos e sustentou que o Espírito e sua interioridade eram o que havia de mais efetivo. Em sua obra Fundamento de toda Teoria da Ciência (1794) ao colocar o "Eu puro" no centro da filosofia teórica e prática, ele construiu um Idealismo da Subjetividade, que influenciou tanto o Romantismo como Hegel. Hegel, por sua vez, teria radicalizado a teoria da Subjetividade a partir da construção de uma "dialética especulativa", na qual elaborou uma Metafísica da Subjetividade Absoluta, tendo sido o ponto culminante do Idealismo alemão.

Assim como os românticos, Hegel considerou a modernidade o momento de transição para uma época radicalmente nova, sendo o primeiro a desenvolver um conceito de modernidade propriamente filosófico. Em Fenomenologia do espírito (1807) o filósofo concebeu a filosofia como um processo histórico, sem, contudo, abdicar de pressupostos racionais e dialéticos. Assim, se Fichte está interessado pela história atemporal do Eu e Schelling pela história do mundo, da arte e dos mitos, Hegel estaria interessado pela "vida do Espírito" que ele considera um procedimento histórico no qual o Absoluto se manifestaria de maneira contínua, progressiva e racional. Sua intenção 
Meireles, T. M.

seria construir uma Filosofia da História, mostrando que o Espírito é história e que a História Universal resulta do Absoluto. No entanto, na visão do autor, Hegel não conseguiu unir satisfatoriamente os movimentos fenomenológicos com os históricos, nem sua Filosofia da História com a Filosofia do Espírito, pois ao valorizar a vida universal do conceito, Hegel teria desvalorizado as transitoriedades históricas. Seu método "dialético especulativo", como o esforço sistemático para elaborar a primazia do Espírito diante das contradições e limitações do mundo histórico e real expôs, contudo, a miséria da filosofia idealista, e nesse momento a história entrou no período da crítica da esquerda hegeliana.

O capítulo 3, intitulado Feuerbach e a esquerda hegeliana é também apresentado em dois tópicos: Feuerbach, Hegel e a esquerda hegeliana e A crítica da religião e a antropologia. Segundo Araldi, a esquerda hegeliana considera-se a herdeira legítima da filosofia de Hegel e Feuerbach (1804-1872) é o filósofo que rompe com a "Direita hegeliana" escrevendo em 1830 a obra Pensamentos sobre a morte e a imortalidade, em que se afasta das tentativas de justificar o Estado e a Religião pela razão. Em 1839 escreve a obra Crítica da filosofia hegeliana, na qual compartilha com outros autores da esquerda hegeliana a proposta de "despotencializar a filosofia". No entanto, Feuerbach é um filósofo recolhido demais para propor a transformação da filosofia em práxis. Ainda assim, foi um importante pensador do materialismo do século XIX, tendo construído uma filosofia como tentativa de reduzir a metafísica e a teologia à antropologia. Com essa redução o filósofo pretendia sustentar a verdadeira essência do cristianismo, que tinha como foco o indivíduo. Sua obra A essência do cristianismo, escrita em 1841, teria sido muito relevante, segundo Engels, por pelo menos dois aspectos: por seu materialismo, a partir de sua concepção de natureza; e pela crítica à religião, que teria influenciado Marx. Segundo Araldi, a antropologia de Feuerbach consiste na compreensão de que todos os resultados da religião

284 | Cad. Nietzsche, Guarulhos/Porto Seguro, v.39, n.3, p. 279-292, setembro/dezembro, 2018. 
Dos românticos a Nietzsche. Oito estudos sobre a Filosofia do século XIX

podem ser reduzidos à essência humana, definida como Razão, Vontade e Coração.

O capítulo 4, intitulado A dialética e a práxis histórica em Marx é apresentado em três momentos: A crítica a Hegel: a miséria da filosofia, A dialética como práxis histórica e Fim da Filosofia, Fim da História? Do círculo dos jovens hegelianos de esquerda, Marx foi o pensador que mais se destacou ao propor a superação da Filosofia a partir de uma crítica da sociedade inseparável da práxis revolucionária. Segundo o autor, a crítica de Marx a Hegel se dá pelo caráter abstrato atribuído ao homem. Hegel concebe a essência do homem como autoconsciência, pensamento puro e nesse sentido, a alienação para ele, é alienação da autoconsciência. Diferentemente, para Marx, a autoconsciência é apenas um aspecto da natureza humana e seu interesse é investigar a "alienação efetiva". Desse ponto de vista, a dialética para ele consistiria no esforço em recuperar as forças essenciais do homem, que foram alienadas, e nasceram para a objetivação, concebendo o homem como ser objetivo e natural. Com relação a sua práxis histórica, o jovem hegeliano propôs uma Filosofia como "crítica interventora", na qual concebeu a possibilidade de transformar a práxis histórica, política e social a partir da tomada de consciência do sujeito humano, em meio às tensões da sociedade. Para ele, esse caminho da sociedade culminaria no "comunismo". O que move o processo histórico, em sua concepção, são as próprias capacidades dos seres humanos: a produção, o trabalho e a práxis social.

O capítulo 5, intitulado Schopenhauer, o pessimismo e o valor da vida, é exposto a partir de três tópicos: $O$ pessimismo na juventude de Schopenhauer, O Pessimismo e a sabedoria dos Antigos e A vontade de viver, o ascetismo e o Nada. Nesse capítulo o autor sustenta que o tema do pessimismo esteve presente no pensamento de Schopenhauer desde sua juventude. Ainda que não tenha sido uma invenção sua, pois o pessimismo já estava presente na Antiguidade, tanto na filosofia como nas religiões, o pensamento de Schopenhauer é considerado ‘a 
Meireles, T. M.

forma mais acabada de pessimismo'. O filósofo pretendeu construir uma metafísica maior, 'verdadeira', que é também uma arte da vida, assente na ascética, sendo esta a proposta de uma "arte de viver pessimista" e afirmativa.

Em $O$ mundo como vontade e representação Schopenhauer desenvolve sua "Verdadeira metafísica" que considera a vontade como o que há de mais essencial e originário, ela é a "coisa em si". Para ele, o mundo dos fenômenos possui em relação ao mundo da representação uma preocupação prática, ética e ascética, que torna difícil justificar uma separação entre o mundo e a vontade. Enquanto "coisa em si", a vontade é a essência do próprio fenômeno, mas ao mesmo tempo em que é independente, ela penetra no mundo para poder se manifestar. Para ele a vontade, ao se manifestar, abre a possibilidade para a "autorredenção". A proposta do filósofo é conceber uma vontade que seja capaz de alterar o próprio querer e assim negar a vontade de viver.

Para ele, a vida é um constante necessitar e o homem é a manifestação concreta do querer que busca incessantemente saciar suas necessidades e logo após é conduzido ao tédio e à dor. A vontade de querer viver é nesse sentido negativa e consiste na passagem para o "nada". Sua perspectiva sobre a vida ocorre, portanto, a partir da recusa no núcleo da vida e do vivente, no sentido de elevar-se acima do querer. Essa perspectiva é "relativa e fugaz", proveniente de um indivíduo que a partir de si, se volta contra os instintos de dentro e de fora de si. Nesse movimento ele pode retornar a si transformado, mas nunca abandona completamente seu ser. A forma mais eficiente de arrancar-se dessa existência, para Schopenhauer, está no âmbito da ascese, mas também da arte e da ética. Assim, em meio às esperanças revolucionárias do século XIX, Schopenhauer quer livrar-se das paixões da vida e das ilusões modernas a partir de uma "arte pessimista de ser feliz". Segundo o autor, o pessimista teria sido um dos primeiros a criticar o pensamento idealista de Hegel,

286 | Cad. Nietzsche, Guarulhos/Porto Seguro, v.39, n.3, p. 279-292, setembro/dezembro, 2018. 
Dos românticos a Nietzsche. Oito estudos sobre a Filosofia do século XIX

por não considerar a efetividade do mundo, os sofrimentos do mundo, que ele compreendia como vontade e representação.

O capítulo 6, de título Kierkegaard: o indivíduo, o desespero e a fé cristã é constituído também por três seções: Kierkegaard e seu tempo, Da estética para a ética: por que Don Juan e Abraão se desesperam? E A doença para a morte. Segundo o autor, o filósofo dinamarquês buscou a superação da filosofia na religião, na fé e no desespero, a partir da estética e da ética. Para ele, o indivíduo decidido a si mesmo só poderia superar o desespero da existência no confronto com Deus. No contexto da existência transitória e angustiante da vida moderna, Kierkegaard sustentou que o indivíduo experimenta possibilidades de liberdade que o levam ao desespero. A angústia está na base da subjetividade própria do ser humano, tanto no estágio estético em que o indivíduo se depara com toda a transitoriedade da vida, como no estágio ético, em que se defronta com seu "eu mais próprio", não podendo se furtar de assumir a tarefa de sua existência. $\mathrm{O}$ desespero, enquanto aspecto abstrato, pode ser considerado em Kierkegaard uma vantagem do ser humano em relação aos outros animais, mas pode também ser visto, como uma das "piores misérias". Para ele é somente pela fé cristã que o homem consegue elevarse acima do desespero, consistindo no ápice do desenvolvimento espiritual do ser humano. Contudo, segundo Araldi, o pensamento de Kierkegaard apresenta um paradoxo filosoficamente desafiador, a partir da concepção de um indivíduo único, como um Si-mesmo, que se eleva diante de Deus.

O capítulo 7, intitulado $O$ positivismo e as ciências no século XIX, apresenta a importância filosófica do positivismo do século XIX com relação as ciências naturais que se consolidavam em todas as esferas da vida humana, em duas seções: Auguste Comte: a física social e a lei dos três estados e Spencer e o positivismo evolucionista. O positivismo de Comte é considerado a expressão do triunfo das ciências naturais no século XIX e também signo de uma nova mentalidade cientificista 
Meireles, T. M.

que tinha pretensão de torna-se a "nova religião". A partir de sua "física social", Comte pretendia compatibilizar a visão humanista com os progressos científicos, mas acabou em uma visão dogmática. Spencer por seu lado, pretendia compatibilizar as aspirações humanas e morais com o pensamento científico a partir de uma ciência moral e social, pela fisiologia. Nesse capítulo vemos os esforços da filosofia para preencher o vácuo da modernidade através da compatibilização com o progresso científico. Será, contudo, com Nietzsche que essas ideias encontrarão uma radicalização mais acentuada e à filosofia ficará a tarefa de "criar novos valores", como tentativa de unir a ciência com a arte.

O capítulo 8, intitulado Nietzsche: a crítica da moral e a filosofia do futuro, é constituído por cinco tópicos: As três transmutações do Espírito, A crítica da moral em Humano, demasiado humano, A crítica da modernidade em Além do bem e do mal, A genealogia da moral e $A$ criação de novos valores e a filosofia do futuro. Nesse capítulo, o autor apresenta os aspectos críticos e criativos do pensamento de Nietzsche, que busca ir além da modernidade ocidental, não só na moral, mas na metafísica e na religião. A partir da ênfase na tarefa afirmativa deixada à filosofia do futuro, como tentativa de compatibilizar a ciência com a "ética-estética", encontramos nesse capítulo um dos projetos mais ambiciosos do século XIX para superar a crise dos valores.

A partir da exposição sobre Das três transmutações, discurso presente em Assim falou Zaratustra, o autor apresenta a tentativa ali presente de "abarcar todo o movimento do espírito humano, da vida do próprio Nietzsche e da história da filosofia ocidental" (p. 117). Segundo Araldi, estaria na base do pensamento de Nietzsche a ideia de uma "transmutação radical" na qual o indivíduo, livre dos valores transcendentes, buscaria ultrapassar a si mesmo para criar novos valores.

Através da criação da Filosofia do Espírito Livre, presente na segunda fase do pensamento de Nietzsche, o filósofo buscaria libertar-

288 | Cad. Nietzsche, Guarulhos/Porto Seguro, v.39, n.3, p. 279-292, setembro/dezembro, 2018. 
Dos românticos a Nietzsche. Oito estudos sobre a Filosofia do século XIX

se dos mestres Schopenhauer e Wagner, que até então marcavam seu pensamento, buscando refúgio na ciência, no filosofar histórico, no positivismo e na psicologia moral de Paul Rée. A proposta de uma 'história efetiva da moral' teria sido realizada nas últimas décadas do século XIX, momento no qual Nietzsche compartilha com Paul Rée a derivação dos sentimentos morais a partir dos sentimentos de prazer e desprazer. Perspectiva que irá mudar na fase tardia, com o desenvolvimento da doutrina da vontade de potência que passa a ser o novo critério para a avaliação dos valores morais.

Em Além do bem e do mal, obra do período tardio do pensamento nietzschiano, a história natural da moral ganharia um novo desenvolvimento a partir do método de análise genealógico. Para Nietzsche, a vontade de potência foi o critério utilizado para criticar não só os valores morais tradicionais, mas também para estabelecer novos e construir uma tipologia da moral, que definiu dois tipos de moral: uma afirmativa, proveniente da moral dos senhores, e uma moral negativa, proveniente da moral dos escravos. $\mathrm{O}$ projeto de naturalizar a moral em Além do bem e do mal encontra, contudo, lacunas que Nietzsche irá tentar preencher em Genealogia da moral. Mas essa obra também não esgota o estudo sobre a história da moral e suas consequências niilistas, deixando a promessa para um estudo que estaria por vir: $A$ vontade de potência que, no entanto, não fora concluída.

Ao distinguir o surgimento de dois tipos de moral, a moral dos senhores e a moral dos escravos, o genealogista mostra que no tipo nobre, o valor de bom, se refere ao que provém dos instintos fortes da vida. Em oposição, ruim, é tudo aquilo que é desprezível e fraco em relação ao nobre, que é forte. Para o tipo de homem da moral escrava a moral nasce a partir da forma de valorar do fraco: o bom é tudo que se opõe ao nobre, guerreiro, forte e dominador, que é considerado mau na moral escrava. Nietzsche compreende a forma de valorar do sacerdote ascético nos seguintes termos: “Ao 'dizer-não' para o odiado nobre, ao voltar-se para fora de sua existência malograda, o 
Meireles, T. M.

sacerdote propriamente não cria, mas inverte valores" (p. 129). A história da moral teria sido assim, dominada por essa inversão dos valores. Para ele, se a moral escrava triunfa é a partir da negação dos instintos afirmativos da vida, considerados bons na moral dos fortes. A análise genealógica, nesse sentido, apontaria a fonte moral não só da verdade e da religião, mas da metafísica e da ciência.

Conforme o autor apresenta, no período tardio das obras de Nietzsche, entre 1885-1888, o filósofo insere o caráter artístico no procedimento de criação de valores. Para Nietzsche, a moral poderia ser justificada como fenômeno estético, na medida em que os juízos e valores morais teriam origem em percepções estéticas, sem o suporte das oposições metafísicas. O projeto de reduzir a moral à estética, presente nos escritos tardios, deveria, contudo, ser questionado. Segundo o autor, esse projeto está no âmbito do indivíduo singular que se colocaria para além do período moral da humanidade. Para Nietzsche, o indivíduo soberano é aquele que, liberado da moralidade dos costumes, é igual apenas a si mesmo. $\mathrm{O}$ indivíduo soberano, considerado um indivíduo singular e autônomo, estaria no final do processo da história universal da moral. Ele encontrar-se-ia, portanto, no período "extramoral", cuja condição é a naturalização do homem, que se torna possível através da investigação genealógica-histórica da moral. Para Nietzsche, a própria moralidade revelaria a imoralidade reinante tanto na natureza como na história.

Para o autor, Nietzsche seria precursor de uma "nova filosofia afirmativa", como intenção de superar a moralidade consolidada no homem moderno. No entanto, teria se restringido a investigar criticamente a história natural da moral e lançado à filosofia do futuro a tarefa de afirmar a si mesmo pela via ético-estética - que consiste na sua tentativa de romper com a crise do mundo moderno. Segundo Araldi, é somente pela arte que a existência pode ser afirmada para Nietzsche. E para propor valores não-morais, como uma arte afirmativa

290 | Cad. Nietzsche, Guarulhos/Porto Seguro, v.39, n.3, p. 279-292, setembro/dezembro, 2018. 
Dos românticos a Nietzsche. Oito estudos sobre a Filosofia do século XIX

de si mesmo, o homem precisa se liberar dos velhos valores herdados da tradição europeia. E nesse sentido, o projeto de naturalizar a moral, auxiliaria na tarefa deixada aos filósofos do futuro.

Ao final de sua trajetória Do Romantismo a Nietzsche, o autor deixa o questionamento: "Num mundo dominado pelas ciências, o que resta para a filosofia?" (p. 136). Esse questionamento encontra ao longo dos estudos selecionados por Clademir Araldi o seguinte desenvolvimento: a filosofia do século XIX buscou na união tanto do Espírito com a Natureza como da Arte com a ciência uma maneira de reagir ao vazio deixado na modernidade. Por meio desses estudos recentes, compreendemos que o filósofo alemão descreveu o espírito moderno a partir do niilismo moral, enquanto um processo que encontra aí sua forma mais radical. Esse sentido já estava presente em seu trabalho anterior Para uma caracterização do niilismo na obra tardia de Nietzsche (1998), a partir da qual percebemos que a criação de novos valores como forma de conceber uma maneira de viver afirmativa torna-se necessária. Em Do romantismo a Nietzsche o autor insere tal problemática no contexto histórico da filosofia moderna e contemporânea que se apresenta como crítica mais radical a esse estado de crise já reivindicado pelos primeiros românticos.

Da subjetividade do gênio criador à tentativa de reduzir a ética à estética a partir de uma análise genealógica dos valores morais, vemos um percurso na história do pensamento ocidental que privilegia a via artística como tentativa de conceber a noção de vida, a partir de um indivíduo, que para além da moral e do progresso tecnocientífico, busca dar um sentido afirmativo à existência. Em nossa concepção, a aposta nos filósofos do futuro, enquanto criadores de novos valores, deixa, portanto, essa tarefa a ser realizada pela filosofia: a de conceber novos valores para a vida, que encontra na trajetória dos românticos a Nietzsche, como herança do ímpeto tempestuoso e ao mesmo tempo criador da modernidade, uma via significativa. 
Meireles, T. M.

\section{Referência bibliográficas}

ARALDI, Clademir. Do romantismo a Nietzsche: rupturas e transformações na filosofia do século XIX. Pelotas: NEPFIL Online, 2017.

. Para uma caracterização do niilismo na obra tardia de Nietzsche. Cadernos Nietzsche, São Paulo, n. 5, p. 75-94, 1998. Disponível em: <http:// www.gen.fflch.usp.br/sites/gen.fflch.usp.br/files/upload/cn_05_05\%20Araldi. pdf>. Acesso em: 30/04/2018.

HOBSBAWM, Eric. A Era das revoluções: Europa 1789-1848. Rio de Janeiro: Paz e Terra, 1998.

Resenha recebida para publicação em 07/06/2018.

Resenha aceita para publicação em 13/08/2018.

292 | Cad. Nietzsche, Guarulhos/Porto Seguro, v.39, n.3, p. 279-292, setembro/dezembro, 2018. 